Meeting report

\title{
National symposium on problems of presymptomatic testing for Huntington's Disease, Cardiff
}

\author{
Audrey Tyler and Michael Morris Cardiff
}

\section{Authors' abstract}

Presymptomatic testing for Huntington's disease has given rise to several ethical problems relating to such issues as confidentiality, the privacy of the individual, the testing of minors and informed consent in connection with blood sample donation. A multidisciplinary conference of staff from genetic centres involved with presymptomatic testing was organised in Cardiff to discuss these and other problems. Recommendations on good practice are described under four headings: pre- and post-test counselling; confidentiality in relation to test results; collection and storage of DNA, and criteria for testing.

\section{Introduction}

Huntingtor's Disease (HD) is an incurable, neurodegenerative disorder of adult onset inherited as an autosomal dominant. The discovery of a closely linked DNA marker in 1983 has made possible presymptomatic testing for the individual at risk. Further markers have since been discovered by American, Canadian and British groups.

The test is not error-free, because of the possibility of recombination. For the applicant who has an $a$ priori risk of 50 per cent of developing HD it is possible to raise it to about 98 per cent or lower it to 2 per cent. Since this depends on a linkage study, the co-operation of other family members in donating blood samples is necessary.

Genetic centres offering the presymptomatic test have encountered unforeseen problems relating to such issues as confidentiality, the privacy of the individual, and the preservation of the right of the atrisk person to choose not to be tested. It quickly became evident that these problems were so complex that discussion in a national conference was needed. Previous guidelines had been issued by a Joint Committee of the World Federation of Neurology and the International Huntington's Association (of which one of us, AT, is a member) in 1985, but, with greater experience, it was felt that more detailed debate was

\section{Key words}

Huntington's Disease; pre-symptomatic testing; ethical problems. urgent.

Sixteen participants, consisting of medical, laboratory and fieldwork staff from genetic centres in England and Wales, attended. Topics for discussion had been previously circulated, and genetic centres which had been unable to send representatives, had sent comments.

\section{Pre- and post-test counselling}

Concern was expressed about the adequacy of counselling, particularly when the test is brought out of the research stage and into service use.

\section{RECOMMENDATIONS}

a) It should be the responsibility of one person to ensure that counselling is adequate and that all relevant issues are discussed. b) If pre-test and post-test counselling are undertaken by different persons, the post-test counsellor should meet the applicant beforehand. c) Sufficient resources should be available for support on demand for persons at low risk as well as those at high risk. d) Provision should be made for the long-term monitoring of the psychosocial consequences of testing.

\section{Confidentiality in relation to test results}

Detailed discussion with the applicant of who should be told the results is needed. The results should not be put into general hospital records and should not be disclosed to other agencies except at the applicant's request. Each applicant is asked to nominate a companion and a professional supporter and these must always be told. Only information relevant to the applicant should be shared with professional colleagues; the disclosure of information which belongs to other family members (inevitable in a linkage study) should be kept to a minimum. Disclosure of results to general practitioners is debatable because of the possible implications for confidentiality and the applicant's children.

Confidential information may be inadvertently disclosed in the process of getting a result, because of the need to involve family members who may be totally disinterested in knowing their status or in counselling.

RECOMMENDATIONS

a) The general practitioner need not necessarily be 
nominated as a post-test supporter. b) A family member's right to confidentiality supersedes the applicant's right to be tested. c) The privacy of other family members should be respected.

\section{Collection and storage of DNA}

The setting up of a central register for the storage of DNA samples was discussed. It was acknowledged that public anxiety would be aroused and that there would be difficulties in maintaining confidentiality and keeping up-to-date records. No consensus was reached.

The status of research samples of DNA considered for later clinical application may need clarification with the donor.

\section{RECOMMENDATIONS}

a) Consent for use of samples for both purposes (ie, research and service) should be obtained and the basis on which blood is being donated made clear. b) Second samples should be sought to minimise the possibility of error and to allow for wastage. c) No typing results attributable to at-risk donors should be used without their knowledge and consent. d) Results should be shared between centres to avoid duplication of tests on irreplaceable samples. e) Requests from other regions for blood samples should be made, initially, to the appropriate genetic centre, to avoid unnecessary sampling.

\section{Criteria for testing}

Though neuropathology to confirm the diagnosis in a family is not essential, particularly where there are several affected members, it is highly desirable.

\section{RECOMMENDATIONS}

a) The co-operation of the family and appropriate professionals should be actively sought and written information offered on post-mortem arrangements. b) For applicants already thought to be affected or showing equivocal signs the test should be postponed and an attempt made to obtain clinical confirmation. c) Close co-operation with a neurologist should be established before a testing programme is undertaken. d) Although no good information exists on the most appropriate age to offer testing applicants still in their teens should be encouraged to take extra time to consider all the implications of being tested. e) Presymptomatic testing of children at risk, who are being placed for adoption, should not be performed, as testing should only be undertaken with fully informed adults who have freely given consent.

\section{Participants}

David Watt, Chairman (Oxford), Alison Boughey (London), David Craufurd (Manchester), Mary Davies (London), Anona Galliard (Oxford), Anita Harding (London), Ann Howick (London), Pat Jones (Cardiff), Laz Lazarou (Cardiff), Linda Meredith (Cardiff), Jackie Moran (Oxford), Michael Morris (Cardiff), Morag Nordin (Swansea), Ann Pedlar (Birmingham), Raj Shiwach (Oxford), Audrey Tyler (Cardiff). Guest: Professor Cantu (Mexico).

A full transcript of the proceedings is available from the authors.

Audrey Tyler MSc AIMSW trained as a medical social worker and has thirteen years' experience in Huntington's chorea research, specialising in epidemiology and psychosocial issues. Michael Morris MB MSc MRCPsych is a Research Senior Registrar funded by the Mental Health Foundation for three years to study the clinical aspects of the new predictive test.

\section{Editor's note}

The journal is keen to publish brief (1500-2000 word) meeting reports. Any reader wishing to contribute such a report should send it to: The Editor, Fournal of Medical Ethics, c/o Imperial College of Science, Technology and Medicine, 14 Prince's Gardens, London SW7 INA. 